\title{
¿Cuál cambio social? Construcción de vínculos políticos en un espacio de mujeres piqueteras
}

Cecilia Cross $^{1}$

Florencia Partenio ${ }^{2}$

\begin{abstract}
Resumen
Este trabajo analiza las experiencias de un grupo de mujeres que conformaron un espacio propio en un movimiento social, el Frente Popular Darío Santillán. Este movimiento impulsa el "cambio social" a partir de la transformación de las prácticas políticas y la superación de "los viejos esquemas de dominación". A pesar de este propósito, conserva una característica que lo equipara a dichos esquemas: la mayor parte de sus líderes eran varones, a pesar de estar compuesto mayoritariamente por mujeres. Este fue el punto de partida para la conformación de un "espacio de mujeres". Desde este espacio las mujeres cuestionaron no sólo la distribución de poder en el movimiento sino también los alcances del concepto de "cambio social". Este proceso es analizado a partir de las herramientas conceptuales que aporta el debate Fraser-Honneth a la reflexión en torno a la vinculación política y la acción colectiva contenciosa.
\end{abstract}

Palabras clave: reconocimiento - redistribución - mujeres piqueteras - articulación de experiencias - vinculación política.

\begin{abstract}
In this paper we analyze the case of women involved in a piqueteros' movement named Frente Popular Dario Santillán. This movement promotes "social change" through the transformation of political practices and overcoming "the old forms of domination". Despite this purpose, it still has a distinctive characteristic shared with other "traditional" institutions: although it was composed mostly of women, the leaders were men. This is the starting point of a "women space" conformation. From this space women have questioned not only the distribution of power within the movement, but also the meanings of social change. In this article we analyse this process from conceptual tools introduced by Fraser-Honneth debate.
\end{abstract}

Key words: recognition - redistribution - picketing women - articulation of experiences - political involvement.

Doctora en Ciencias Sociales, Universidad de Buenos Aires (UBA), Argentina. Politóloga. Investigadora CONICET con sede en CEIL-Piette, Buenos Aires.

2 Doctoranda en Ciencias Sociales y Socióloga por la Universidad de Buenos Aires (UBA), Argentina. Feminista lesbiana, investigadora asociada en CEIL-Piette y docente de la UBA. 


\section{INTRODUCCIÓN}

Este trabajo analiza las experiencias de un grupo de mujeres que conformó un espacio propio en un movimiento piquetero: el Frente Popular Darío Santillán (FPDS). Este proceso les permitió cuestionar no sólo la distribución de poder en el movimiento, sino también el sentido de su acción política, definida en términos de "cambio social"3. En este artículo, analizamos dicho proceso a partir de las herramientas conceptuales que aporta el debate Fraser-Honneth (2006) a la reflexión en torno a la vinculación política y la acción colectiva contenciosa.

A continuación presentamos resultados de investigaciones comenzadas en 2004, en las que articulamos enfoques cualitativos y procesos de investigación-acción participativa con el fin de producir conocimientos situados (Haraway, 1995). Los datos con los que trabajamos han sido elaborados combinando técnicas afines a la tradición cualitativa, como la observación, el desarrollo de entrevistas en profundidad y el análisis documental, con talleres vivenciales, espacios participativos orientados al diseño de documentos y materiales de difusión.

Mediante este enfoque buscamos enriquecer en dos sentidos el concepto de intervención (Brincker y Gudenlach, 2005): por un lado, nos orientamos hacia preocupaciones de índole académica, tales como el estudio de la articulación de experiencias en varones y mujeres de sectores populares, que elaboramos a fin de enriquecer e interrogar la teoría a partir de los resultados de nuestra investigación; por otro, analizamos las experiencias compartidas con las mujeres de un movimiento social, el FPDS, con el propósito de aprehender el camino recorrido como insumo desde el cual pensar(se) la propia práctica.

De este modo, en el próximo apartado presentaremos las herramientas analíticas y las interrogantes con las que trabajaremos en este texto. Luego, a fin de dar cuenta del camino efectuado por estas mujeres, contextualizaremos la conformación del FPDS para, posteriormente, recorrer las demandas definidas en el espacio de mujeres. Finalmente, reflexionaremos acerca de los aportes de un enfoque basado en el estudio de las experiencias para comprender los procesos de movilización política.

\section{LA VINCULACIÓN POLÍTICA, LAS EXPERIENCIAS Y LA LUCHA SOCIAL}

A lo largo de los últimos 40 años se ha desarrollado una extensa producción académica acerca de los procesos de movilización social y sus implicancias en términos

A lo largo del artículo, cuando no se indica una fuente bibliográfica frente al uso de comillas, éstas señalan el uso de categorías nativas que permiten reconstruir las narrativas analizadas a fin de poder diferenciar entre interpretaciones de las autoras y los discursos, juicios de valor y declaraciones de principios relevados en los registros de campo. 
de integración política de las diversas identidades sociales, culturales y políticas que pugnan por expresarse cotidianamente en el espacio público (Tejerina, 1998). Los principales exponentes de estos enfoques han pensado los procesos de movilización en tanto acción colectiva, ya sea aquellos vinculados al estudio de nuevos movimientos sociales (Offe, 1985; Melucci, 1999) desarrollados en Europa continental o la vertiente anglosajona vinculada a las teorías de movilización de recursos (Zald y Mc Carthy, 1987; Tarrow, 1994).

También en Argentina los diversos procesos de movilización que se manifestaron desde los '80 han sido pensados en esta clave. En particular, la movilización piquetera se ha explicado como "respuesta" a las carencias materiales que padecen sus participantes (Schuster y Pereyra, 1999; Svampa y Pereyra, 2003) y/o a los déficits del modelo de democracia construido en los'80 (Calvo, 2003; Merklen, 2005). Desde esta perspectiva, se confunde la demanda expresada con el sentido de la movilización, dotando a los actores colectivos -el gobierno, los movimientos, los partidos, etc.- de una racionalidad unificada, opacando los procesos de conflicto y acuerdo, de reflexión y transformación que tienen lugar entre quienes integran esos espacios (Cross, 2010).

En este marco, el debate entre Axel Honneth y Nancy Fraser (2006) constituye un valioso aporte porque ofrece una clave para articular subjetividad y movilización a partir del concepto de luchas por el reconocimiento. Este concepto recupera las tesis de Hegel en Jena, según las cuales la individuación es producto del encuentro con otros/ as semejantes y no un a priori del sujeto, lo cual permitiría romper con "los supuestos de la teoría moderna desde Maquiavelo y Hobbes hasta Nietzsche" (Honneth, 1997: 115). Honneth propuso considerar tres formas de reconocimiento, a saber: amor, derecho y solidaridad, los cuales constituyen los parámetros intersubjetivos de protección que permiten alcanzar aquellas condiciones que "aseguran" la "libertad interior y exterior", a la cual está "destinado" el proceso de "una articulación y realización no forzada de los objetivos de vida individual". De esta forma, los/as destinatarios/as de toda acción serían precisamente otras personas, con lo cual "el genérico proceso histórico de individuación" se encontraría ligado a "una simultánea expansión de las relaciones de reconocimiento recíproco". Así, "los cambios sociales normativamente orientados" serían impulsados por "las luchas moralmente motivadas" en "el intento colectivo de proporcionar la implantación de formas ampliadas de reconocimiento recíproco institucional y cultural" (Ibíd: 210).

En un escenario como tal, la lucha social se define como el proceso práctico que permite articular colectivamente las experiencias de menosprecio sufridas singularmente. Dichas experiencias, que constituyen fuente de "humillación"y"pérdida del autorrespeto", tienen lugar cuando las "expectativas de autorrealización" de un sujeto no coinciden con aquello que el horizonte normativo socialmente vigente establece como fuente de estima social. En cuanto a las fuentes de menosprecio, el autor considera que toda humillación personal constituye una falta de reconocimiento. A su modo de ver, la distribución desigual de recursos es producto de procesos sociales de menosprecio 
y no puede distinguirse ontológicamente de humillaciones padecidas en virtud de la condición de género, las creencias religiosas o las ideas políticas.

Frente a esta conceptualización, Nancy Fraser (2000) - desde una mirada feminista y marxista no ortodoxa que otorga preponderancia a los factores estructurales del tándem menosprecio/reconocimiento- propone atender de forma diferenciada, aunque articulada, las fuentes de menosprecio relacionadas con los grandes procesos de humillación que impone la sociedad occidental: desigualdad en la distribución y negación de las singularidades. De este modo, llamó la atención, a propósito de la importancia de no descuidar la pobreza como experiencia de menosprecio peculiar, que no debe equipararse a otras faltas de reconocimiento. Así, la autora distingue las luchas por el reconocimiento que buscan consagrar el respeto por diversas identidades de aquellas orientadas a lograr una mayor equidad en la distribución de recursos. De este modo, a partir del concepto de "paridad participativa", postula la necesidad de mantener la vigencia de ambos horizontes: igualdad en la distribución y reconocimiento de la diversidad (Fraser, 1997).

Nuestra investigación, en tanto trabajo cualitativo, no busca zanjar empíricamente esta discusión teórica. En cambio, propone recuperar como eje central de análisis una pregunta que atraviesa este debate: ¿cómo se articulan las demandas expresadas colectivamente con las experiencias singulares de quienes se vinculan a un movimiento social? Consideramos que analizar las experiencias de las mujeres del FPDS desde este enfoque resulta adecuado en tanto constituyen un ejemplo paradigmático para estudiar esta cuestión, al definirse como mujeres y pobres (Ibíd.).

Además, creemos que las teorías del reconocimiento son un aporte central al estudio de los movimientos sociales porque rompen con supuestos arraigados en las teorías de la acción colectiva, principalmente en lo que refiere a la figura del actor (colectivo), concebido como la sumatoria de individuos (cartesianos) identificados exclusivamente desde la demanda que caracteriza al movimiento (desocupados, gays, ecologistas, etcétera). La subjetividad para Honneth y Fraser no es a priori sino que se construye en el proceso de socialización. Este desplazamiento permite descentrar cualquier tipo de racionalidad como explans de la acción. A su vez, al plantear la articulación compleja entre experiencias singulares y lucha social rompen con el supuesto según el cual es posible atribuir al actor colectivo una racionalidad unificada derivada de la demanda expresada públicamente (Cross, Op. cit.). Sin embargo, ni Fraser ni Honneth se detienen particularmente en el concepto de experiencia.

Este concepto tiene una larga tradición en la fenomenología y constituye un eje de debate de las ciencias sociales y humanas (Throop, 2003; Bach, 2008). Excede los propósitos y el alcance de este trabajo dar cuenta de tal debate, pero, en cambio, consideramos indispensable explicitar que en este artículo trabajaremos con el concepto de experiencia propuesto por Teresa de Lauretis (1992). Según esta autora, la experiencia es el proceso continuo e inacabado que permite constituir la subjetividad, 
a partir del compromiso personal en las "actividades, discursos e instituciones que dotan de importancia (valor, significado, y afecto) a los acontecimientos del mundo" (Ibíd: 253). Consideramos que con estas herramientas resulta posible aportar a un enfoque que aborde las luchas sociales desde la praxis cotidiana y las experiencias de las personas que las sostienen, evitando generar perspectivas racionalizadas del vínculo político.

\section{COORDINADORA ANÍBAL VERÓN: EN BUSCA DEL CAMBIO SOCIAL}

El FPDS está conformado principalmente por organizaciones barriales, aunque también por agrupaciones estudiantiles universitarias y de trabajadores/as asalariados/as, cooperativas rurales y de trabajo, que confluyeron como resultado de su vinculación con la movilización piquetera en el conurbano bonaerense. Este proceso, iniciado a fines de los '90, se caracterizó por el corte de ruta o "piquete" sostenido por tiempo indeterminado, a veces por varios días y hasta por semanas. La consigna que identificó a estos movimientos fue la demanda por "trabajo" y quienes se movilizaban se definían a sí mismos/as como "trabajadores/as desocupados/as". El piquete "se levantaba" cuando se "acordaba"la implementación de programas sociales que paliaban la situación de pobreza en que estaban sumidos "los barrios" frente al aumento del desempleo y la precariedad laboral registrados a lo largo de toda esa década. Así, la consecución, distribución y seguimiento administrativo de programas que adjudicaban "planes" (subsidios estatales al desempleo que exigían contraprestación laboral de 4 horas diarias en actividades comunitarias) y"mercadería" (alimentos frescos y secos) se convirtió en el principal organizador de la vida cotidiana para las personas vinculadas a estas organizaciones.

Ahora bien, en un contexto de focalización de la política social, obtener recursos no sólo requería pericia técnica para completar formularios sino capacidad para llevar a cabo y sostener movilizaciones masivas. Para alcanzar esta "masividad" las organizaciones tendieron a confluir entre sí en nucleamientos mayores de amplia extensión territorial. En este contexto, el énfasis de las demandas estaba puesto en la condición de pobreza de las personas movilizadas, la cual se asociaba en forma directa con su situación de trabajadores/as desocupados/as y/o precarios/as. Sin embargo, estas personas no eran necesariamente desocupados/as en sentido estricto, pues en muchos casos se trató de mujeres que no formaban parte de la población económicamente activa.

En este marco, a mediados de 2001 se conformó la Coordinadora Aníbal Verón (CAV) como punto de encuentro entre organizaciones barriales y estudiantiles. Se distinguió de otros espacios piqueteros declarándose prescindente y hasta antagónica de expresiones partidarias y sindicales. Cada una de las unidades territoriales que componían la CAV adoptó el nombre de Movimiento de Trabajadores Desocupados o MTD. Estos 
MTD se distinguían entre sí adjuntando a esta sigla la denominación de la localidad ${ }^{4}$ en que se desempeñaban. Como ocurrió en todos los movimientos piqueteros a fines de los ‘90, en la CAV la "aceptación de los planes" se decidió luego de arduos debates.

La cuestión a dirimir era si acaso demandar "planes" no llevaba a reproducir las "relaciones clientelares" que establecían los partidos políticos. Este debate se plasmó en los "ejes de acumulación" orientados a lograr una práctica "superadora" que les permitiera diferenciarse de los partidos "tradicionales", considerados "autoritarios" y "clientelares", y a impulsar una transformación profunda de las relaciones sociales, basada en la "relevancia del trabajo" como instancia de "creación de valor y realización personal".

Estos "ejes" dieron lugar, según hemos podido documentar, a "consignas"y"principios orientadores" que caracterizaron a los MTD que confluyeron en la CAV. Las primeras, involucraban los conceptos de "Trabajo, Dignidad y Cambio Social". Por su parte, los principios orientadores incluían: i) la "autonomía", definida como independencia del Estado y sus instituciones, de los partidos políticos, de las estructuras sindicales y de la Iglesia; ii) la promoción de emprendimientos productivos para crear trabajo fuera de la "lógica capitalista"; y iii) la "coordinación" como opuesta a la "centralización de las decisiones", lo cual otorgaba preeminencia a las "asambleas" de los MTD por sobre las reuniones de "comisión" y ofrecía la posibilidad de "coordinar la acción con otros movimientos populares que expresasen objetivos comunes". Estos ejes ponen de manifiesto el acentuado lugar que tenía el desempleo como lo que podemos denominar, en términos de Honneth (1997), "experiencia de menosprecio". De hecho la asociación del trabajo a la dignidad (como aspiración singular) y el cambio social (como búsqueda colectiva) da cuenta de las connotaciones que adquiría esta demanda como organizadora de la lucha social en este movimiento.

En cuanto a la composición de los MTD, la mayoría de sus integrantes eran mujeres. Para comprender esto, se puede poner el acento en ciertos factores de contexto: en primer lugar, las políticas sociales que estas organizaciones gestionan han estado dirigidas en modo predominante, sobre todo a partir de 2002, a "jefes y jefas de hogar". Ciertamente, en los asentamientos y barrios populares predominan los hogares monoparentales con jefa de hogar mujer (Partenio, 2009). Entonces, la mayor presencia de mujeres en este tipo de organizaciones, especializadas en los últimos años en gestionar programas sociales, podría explicarse tanto por la composición de los hogares como por la definición de la población beneficiaria de dichos programas. Asimismo, hemos relevado que en aquellos hogares donde hay un varón, éste se dedica a con-

La organización estatal local en el conurbano bonaerense reconoce dos tipos de divisiones: los municipios o partidos y las localidades. Cada municipio involucra tres o más localidades. Siendo la localidad una división formal, es posible encontrar en cada localidad más de un "barrio", entendido éste como una construcción consuetudinaria en función de atributos no siempre idénticos. 
seguir "changas" (empleos temporarios de baja calificación), mientras a las mujeres les corresponde "rebuscárselas en el barrio" para no descuidar las tareas domésticas.

Sin embargo, el relato más extendido entre nuestros/as entrevistados/as resalta la figura de la "mujer piquetera" como "luchadora". Frente al desempleo de los varones, sumidos en la desesperación, las mujeres salieron a "pelear el pan de los/as hijos/as"y el suyo propio. Así, el acercamiento de estas mujeres es interpretado en clave de lucha. No obstante, en la mayor parte de los casos esta lucha se acotaba al espacio comunitario o barrial como prolongación del espacio doméstico. Así nos fue explicado por un líder:

"Los varones en general están más preparados para participar de las cuestiones políticas, las mujeres tienen mayor sensibilidad y por eso son insuperables en lo reivindicativo, en dar una palabra de aliento, en cuidar a los compañeros... Y de eso se trata la organización popular: cada uno en los lugares donde mejor puede servir al ideal de todos. No te digo que no tengamos problemas, pero esta forma de organizarnos nos viene dando buenos resultados, creo, porque como clase estamos todos unidos por los mismos problemas, varones y mujeres" (Mariano, 35 años).

Mariano diferencia los roles a partir de la distinción entre aspectos "reivindicativos" y"políticos" de la lucha. Los primeros involucraban las "actividades comunitarias", tales como organización y atención de comedores, gestión de los formularios exigidos por los programas sociales, organización y clasificación de donaciones, distribución y preparación de alimentos, entre otras. Los aspectos reivindicativos estaban a cargo de las mujeres, llamadas "referentes", que desarrollaban buena parte de sus actividades en el "barrio". Por otro lado, los aspectos "políticos", que involucraban la negociación con funcionarios/as, el tejido de alianzas con líderes de otras expresiones y la representación de la organización territorial en instancias de articulación provincial o nacional, eran asumidos por "voceros/as" ${ }^{\prime \prime}$ que generalmente eran varones, lo cual era justificado por Mariano recurriendo a estereotipos de género ampliamente difundidos.

Este reconocimiento de las diferencias no es de los que permiten ampliar los horizontes de reconocimiento que plantean Fraser y Honneth. De hecho, al señalar dos ámbitos diferenciados se sancionan asimetrías de poder en el movimiento, adjudicados en virtud de la condición de género.

Y aunque sostiene la diferenciación de tareas en base a la condición de género, Mariano introduce la idea de clase como unificadora en términos de intereses, de problemas compartidos. De este modo, instaura una jerarquización del tipo de demanda,

El hecho de que se les llamase voceros y no dirigentes tenía que ver con lo que se entiende como "democracia de base", que postula la rotación permanente en la función y la preeminencia de la asamblea sobre las reuniones de voceros/as. De este modo se buscaba evitar la reproducción de "los viejos esquemas de dominación" (Frente Popular Darío Santillán, 2004). 
estableciendo que aquellas vinculadas con la condición de clase deben primar sobre las relativas a la condición de género. Estos argumentos fueron resistidos por algunas mujeres, negando este falso antagonismo. Así nos fue contado por una mujer del MTD Capital:

[En] los espacios de dirección un poco más de las líneas políticas, digamos, o de las instancias negociadoras... por lo general, no suelen ser mujeres. (...) Es cierto que es como un poco más injusto, como que para la mujer... le cuesta más llegar a esos lugares. Le cuesta más por... por millones de cosas, ¿no?, porque después una quiere garantizar lo del día a día y una se preocupa mucho por llegar al día a día y le cuesta despegarse (...) Entonces, hay cosas prácticas concretas, pero lo que pasa es que de repente hay que ponerse a pensar, que si la mujer tiene tanta práctica en el organizar los barrios... es que realmente... son referentes de los movimientos... es como un poco injusto (...) Por eso nos tuvimos que empezar a organizar nosotras" (Liliana, 38 años).

Al igual que Mariano, Liliana observaba un gran protagonismo de las mujeres "en los barrios", en las actividades comunitarias. También notaba que en los ámbitos de "dirección", donde se establecían las "líneas políticas", no resultaba habitual encontrar mujeres. Para Liliana no se trataba de que existiera una esencia diferente, sino que veía un obstáculo para ella y sus congéneres en la posibilidad de "despegarse" de las preocupaciones que conllevaba "garantizar el día a día". En tanto la resolución de los problemas cotidianos recaía en las mujeres, les resultaba muy difícil poder atender los debates acerca de la coyuntura política o participar en las -larguísimas- reuniones "políticas". La puesta en común de estas experiencias singulares, aunque compartidas, permitió, primero, la articulación colectiva de este modo de distribuir los roles como una experiencia de menosprecio y, en un segundo momento, la concienciación ${ }^{6}$ de estas mujeres, algo indispensable para ponerse en acción.

El reconocimiento de que este modo de relacionarse encierra una "injusticia" es la evidencia de este proceso, y este fue el escenario en que las mujeres de la entonces CAV comenzaron a organizarse.

En el momento en que se comenzaba a instrumentar esa organización de las mujeres, y producto de esta y otras tensiones, la CAV se disolvió. Una de las facciones escindidas dio lugar a la conformación del FPDS. Como pasó con otras facciones, el FPDS conservó muchos de los valores y consignas de la CAV, particularmente en lo referido a "la autonomía"; la práctica de la "democracia de base"; el impulso de proyectos autogestivos; la "formación política" de sus integrantes y la "horizontalidad en 
la organización" (Partenio, Op. cit.). Pero así como muchos valores permanecieron, se mantuvo la división generizada de roles y, junto con ella, la resistencia de algunas mujeres frente a esta injusta distribución del poder en el movimiento.

\section{UN ESPACIO DE MUJERES: OTRO CAMBIO SOCIAL ES POSIBLE}

El cuestionamiento a esta atribución generizada de roles comenzó con una preocupación muy concreta. Así nos fue relatado:

"Y bueno, pero muchas veces pasa que... -y esto te lo van a decir muchas compañeras- a veces nosotras nos quedamos en esta cosa de nuestras propias trabas internas, por decirlo de alguna forma, ¿no? (...) Como una cosa cultural y decimos: '¿qué voy a hacer yo?', ¿qué voy a decir yo?', 'no me voy a animar'o 'no voy a hablar"' (Ema, 52 años, responsable del Área de formación).

Según relata Ema, este proceso comenzó como un modo de enfrentar las dificultades que muchas mujeres encontraban para "hacer"y"hablar", atribuidas inicialmente a "trabas internas". A mitad de camino entre una "esencia" ajena a lo "político" y más proclive a lo reivindicativo y una mirada en términos de "injusticia de género", esta conceptualización nos reenvía al concepto de autorreificación de Honneth (2007). De acuerdo con el autor, la autorreificación es el resultado del "olvido del reconocimiento de sí". Un sujeto capaz de relacionarse expresivamente consigo mismo (es decir, sin autorreificarse) debe poder "aprobarse a sí mismo en una medida tal que le permita considerar las vivencias psíquicas propias, dignas de ser descubiertas activamente y de ser articuladas" (Ibíd: 121-122). En este sentido, las preguntas "¿qué voy a hacer yo?" o "¿qué voy a decir yo?" constituyen una forma de negar la validez de la propia experiencia. Esta constituye una de las principales formas de sostén de las desigualdades de género, en tanto reproduce las "estructuras elementales de la violencia" (Segato, 2003).

El hecho de que estas "trabas" que experimentaban muchas mujeres se relacionen con modelos desvalorizados aprendidos desde la infancia y no con impedimentos particulares, se pone de manifiesto al considerar la impronta que adquirieron ciertas vivencias contrarias a estos modelos, como la que se relata a continuación:

"El Espacio de Mujeres nace del Encuentro Nacional de Mujeres que se hizo en Rosario. Porque acá lo que se dio fue esto, compañeras militantes feministas, trabajadoras sociales, estudiantes, que nos invitan a participar del Encuentro Nacional. Y en el acto de apertura nos empezamos a encontrar, jéramos un montón de compañeras que estábamos ahí! y decíamos 'no puede ser que vengamos particularmente, individualmente... Y bueno, así que ahí empezó a generarse esto... Y bueno, empezamos a clarificar bien entre nosotras de qué manera empezamos a armar estrategias y sale esto de que tenemos que trabajar mucho la dificultad que nosotras tenemos para participar en los ámbitos más generales. O sea que hasta los barrios nosotras no tenemos ningún problema y se labura y bien, pero después no pasamos de ahí. Y cuando fuimos con la postura a la Coordinadora [la CAV], ahí 
empezamos a encontrar un poco... digamos, algunos compañeros muy en contra..." (Josefina, 41 años, vocera del FPDS).

Los Encuentros Nacionales de Mujeres son autoconvocados y se realizan ininterrumpidamente desde 1986 en distintas ciudades de Argentina. Durante tres días se realizan talleres de temáticas diversas (como trabajo, sexualidad, aborto, lesbianismo, economía social, trata de personas, etc.), actividades culturales y movilizaciones. En el encuentro realizado en Rosario en 2003, a partir de la interacción con otras mujeres que les confirmaron la validez de sus aspiraciones de participar "más allá del barrio" en espacios de "decisión política", este grupo identificó la necesidad de "trabajar" para enfrentar sus "dificultades". Siguiendo a De Lauretis (2000), interpretamos que en este marco la subjetividad de estas mujeres inicia"un proceso de actividad reflexiva" -como el que proponen en los Encuentros-y da lugar a prácticas vinculadas a una de-reconstrucción de género, que proporcionan una "capacidad de obrar", "recursos de poder" o que "habiliten investiduras" (61-62).

En este camino, un primer paso fue convocar a "otras compañeras", tarea que fue realizada por un grupo reducido de pioneras", la mayor parte de las cuales cumplía por entonces una tarea de "responsabilidad" dentro de un "área de trabajo" del movimiento. Estas mujeres tenían una larga trayectoria militante en organizaciones revolucionarias de $\operatorname{los}^{\prime} 70$, en organismos de derechos humanos y/o en el feminismo. Otras, sin embargo, estaban iniciando su militancia política y ocupaban roles de referentes o participantes de base. Este grupo fue acompañado por mujeres con militancia estudiantil y en agrupaciones feministas, que dieron un fuerte impulso al proceso.

Como era señalado por las pioneras, esta iniciativa no fue bien recibida por "algunos compañeros", quienes estuvieron "muy en contra" de una "Asamblea de Mujeres". No obstante, ellas impulsaron diferentes acciones para convocar a sus "compañeras", por ejemplo, a través del encuentro mensual en "los piquetes del 26 en el Puente". Éste se llevaba a cabo todos los días 26, desde junio de 2002, para reclamar por el esclarecimiento de los asesinatos de Kosteki y Santillán ${ }^{8}$, aglutinando a todos/as los/ as participantes de la CAV. Por ello fue elegido para promover la creación de un espacio específico de encuentro entre "las mujeres" para tratar sus "dificultades". Luego de mucho esfuerzo, en ese lugar se llevó a cabo la primera "Asamblea de Mujeres", que no fue bien "mirada" por algunos "voceros". Esta asamblea resolvió convocar al "Primer plenario de mujeres", realizado a fines de 2003. Allí, las mujeres manifestaron sus dificultades para participar en política, pero también sus preocupaciones acerca de la distribución de responsabilidades en el cuidado de los/as hijos/as, la maternidad

Tomamos el término pioneras del trabajo sobre el Movimiento de Mujeres Agropecuarias en Lucha (Giarraca, 2001).

8 Ambos eran militantes de los MTD y fueron asesinados por la policía en las inmediaciones del Puente Pueyrredón en el marco de una movilización celebrada el 26 de junio de 2002. 
y el ejercicio de la sexualidad. A partir de lo observado, es posible destacar que estas cuestiones eran vividas como "novedosas", no en relación con la propia cotidianidad, sino como temas a tratar en tanto participantes del movimiento.

Fue así como, a través de los primeros encuentros que se realizaron, las mujeres de los MTD encontraron un momento en el cual discutir sus inquietudes comunes, como mujeres, militantes, madres -la mayoría-y "desocupadas". En este proceso, las pioneras alentaron a otras mujeres para que, además de expresarse, se involucrasen en la organización y coordinación de actividades. Para hacerlo, promovieron la reflexión entre "las mismas compañeras del movimiento" o, como resumía una de ellas, "haciendo, más que planteando cosas". En este proceso, como veremos más adelante, las connotaciones del rol materno, el ejercicio de la sexualidad y la participación política fueron objeto de reflexión y discusión y adquirieron diversos status entre las "prioridades" del Espacio de Mujeres.

Además de las reuniones "en el Puente", se organizaron encuentros que adquirieron el formato de "talleres vivenciales". En estos talleres la acción de relatar se convierte en una práctica central, nutriendo al grupo con testimonios que expresan vivencias personales profundas, relacionadas usualmente con temas desvalorizados o censurados en otros espacios sociales (Gorlier, 2004). Los lugares elegidos para estas prácticas fueron los espacios "comunitarios" de diferentes barrios (Partenio, Op. cit.).

Luego, para fortalecer el espacio, se amplió la convocatoria a mujeres de otras organizaciones vinculadas al FPDS, más allá de los MTD. Por ese entonces, la Asamblea fue rebautizada como Espacio de Mujeres del FPDS. La articulación con grupos feministas y de mujeres se produjo a través de distintos talleres temáticos sobre violencia, salud sexual y reproductiva, intervenciones artísticas y movilizaciones callejeras, como la del Día Internacional de la Mujer o el Día Internacional por la No Violencia hacia las Mujeres. Posteriormente, se consideró la necesidad de crear espacios de "formación política" bajo la modalidad de "campamentos de mujeres", con eje en la "formación en géneros", pensados como jornadas de debate y trabajo en comisiones sobre diferentes temáticas (sexualidades, derechos sexuales y reproductivos, luchas históricas de las mujeres y del feminismo, etc.).

Desde el año 2007 se han realizado cuatro "campamentos nacionales" con la participación de más de 200 mujeres vinculadas al FPDS en distintas provincias. Estas prácticas se presentan como un punto de llegada para las mujeres que venían participando en diferentes "talleres vivenciales", pero, al mismo tiempo, como punto de partida por los desafíos que se abren a partir de las definiciones colectivas y los debates políticos que acarrea en el movimiento. La necesidad de sostener estas prácticas de formación, movilizaron a las mujeres del "Espacio" para tratar de multiplicar la presencia de "otras compañeras" en los encuentros. De esta manera, la forma de construcción del Espacio de Mujeres se fue asentando en prácticas de encuentro, formación y articulación (Ibíd.). 
La realización de los encuentros puso de relieve la necesidad de "garantizar" la asistencia de cada "compañera", lo cual implica considerar las dificultades que se les presentan cuando deben "delegar" el cuidado de sus hijos/as menores (en familiares, parejas, etc.). Esta cuestión se tradujo en la necesidad de demandar en diversas agencias estatales la creación y extensión de espacios educativos y "jardines maternales", lo que ha sido una de las cuestiones que tomó mayor relevancia dentro de los planteos en el propio movimiento y como exigencia al Estado. No obstante, lo más difícil fue instalar la cuestión de que esta demanda era "política"y no "meramente reivindicativa".

En tal sentido, los testimonios coinciden en señalar que hubo menos dificultades en sumar adhesiones a la "jornada por el día de la mujer" o la "marcha contra todas las formas de violencia hacia las mujeres" que para cuestionar las "formas de construcción" política del movimiento y las implicancias del "cambio social" que perseguían. De este modo, las mujeres comprendieron la necesidad de llevar la discusión acerca de estas problemáticas, que desde hacía tiempo venían sosteniendo en el Espacio, a las máximas instancias de debate político del movimiento. También sabían que, para eso, debían actuar con "paciencia y firmeza".

Con este propósito se organizaron con vistas al "plenario nacional" que tuvo lugar a mediados de 2007, en el marco del cual esperaban que el FPDS se definiera como "antipatriarcal". Para ello, comenzaron varios meses antes a confeccionar una "cartilla de formación", que sirvió para difundir e impulsar el debate, primero, en los distintos MTD y agrupaciones que lo conforman y, luego, en las comisiones de trabajo de dicho plenario.

Después de dos largas jornadas de intercambios y debates, finalmente se aprobó definir el FPDS no sólo como un movimiento "anticapitalista", "antiimperialista", sino también como "antipatriarcal". En ese marco, se elaboró una serie de definiciones como "propuestas de lucha", en las cuales se incluyó la necesidad de

"garantizar la participación orgánica igualitaria entre varones y mujeres a través de la atención de niños/as durante las diferentes actividades de la organización y cumplir con los cupos de participación en actividades de formación; potenciar la lucha antipatriarcal a través de la multisectorialidad del FPDS; mantener el 'Espacio de Mujeres' pero a la vez impulsar instancias mixtas que incluyan diferentes identidades de género; generar espacios donde los varones puedan compartir problemáticas; modificar el lenguaje de canciones que signifiquen insultos para la mujer; incorporar en los documentos públicos y conversaciones las terminaciones 'os/as' para referirse a 'compañeros y compañeras'; impulsar el debate sobre la despenalización del aborto en los distintos sectores y organizaciones; que el debate y las acciones de géneros sean transversales a los espacios, áreas y otras instancias del movimiento; trabajar sobre la contención de mujeres que padecen violencia doméstica (Plenario Nacional, nota de campo, julio de 2007). 
Las implicancias que esta declaración tuvo para el conjunto del FPDS se fueron plasmando en el tiempo. Una de las primeras cuestiones que se planteó fue el rol de los "compañeros"varones del FPDS en la "lucha antipatriarcal"9 l lo que llevó a convertir los últimos dos campamentos nacionales en espacios de "formación mixta" con la inclusión de "los compañeros", originando nuevos debates en torno al "cupo" de "los" participantes y en cuanto al cumplimiento en la asistencia.

Asimismo, algunas cuestiones siguen pendientes de resolución, como el caso que genera mayores controversias: la demanda conjunta por el "derecho al aborto legal, seguro y gratuito", que ha logrado instalarse como un problema a debatir en los barrios, con los "compañeros varones" y en las instancias de "formación política" colectiva del movimiento.

Por otra parte, resulta interesante analizar la definición política que este grupo de mujeres tomó para sí al definirse como feministas. Algo de esto puede verse en el siguiente extracto de la "Cartilla de Formación" del Espacio:

\begin{abstract}
"Algunos y algunas que se plantean como anticapitalistas no incorporan la lucha antipatriarcal y muchos feminismos sostienen que la pelea no es contra el capitalismo, sino primero contra el patriarcado (...) Nosotras queremos un feminismo que nos involucre a todos y a todas, que sea combativo, activo, antipatriarcal, anticapitalista, en las calles y por el cambio social" (Espacio de Mujeres del FPDS, 2007: 6-10).
\end{abstract}

En este párrafo se plantea claramente la tensión entre lo que con Fraser (1997) podríamos llamar lucha contra la injusta distribución y lucha por el reconocimiento, como algo presente en el campo político. Las mujeres vinculadas a este espacio plantean la necesidad de un "feminismo" que incluya el rechazo a la explotación capitalista, pero también al "patriarcado", como dos cuestiones que deben ser articuladas.

En tal sentido, se señala un proceso de elaboración de la tensión entre las luchas de clase y de género, que nos permite interpretar que los/as interlocutores/as imaginados/ as para este párrafo son fundamentalmente los/as propios/as compañeros/as. Basta recordar que en un taller sobre "mitos acerca del feminismo", una de las cuestiones que conllevó mayor discusión se originó a partir de la afirmación según la cual "las feministas odian a los varones". Esto dio lugar a un debate acerca de cómo distinguir el patriarcado como impedimento para llevar una vida plena de los varones como compañeros de vida y de lucha por un mundo mejor. Esta discusión fue tan movilizante que muchas la recuerdan como el momento en que decidieron íntimamente sumarse al Espacio

Si consideramos las genealogías de la historia feminista encontramos que esta misma cuestión también se presentó entre las feministas socialistas de los países centrales que en las décadas del '70 y'80 cuestionaron las prácticas del marxismo clásico (Molina Petit, 2007). 
al comprender que "para estar mejor como mujer no tenía que dejar a mi marido y a mis hijos... aunque sí educarlos mejor" para "no reproducir el patriarcado" (Carmen, 35 años, Área de Alimentos. Recientemente integrada al Espacio de Mujeres).

Testimonios como éste ponen de manifiesto la importancia de las vivencias subjetivas en este proceso, en el que un grupo de mujeres comenzó a reunirse para vencer su timidez al hablar en público y terminó debatiendo el sentido del cambio social para todo el movimiento. En términos del debate Fraser-Honneth, este proceso muestra la profunda imbricación entre distintas fuentes de menosprecio que se ponen en juego en la lucha social. En este sentido, la principal característica entre la condición de pobreza, que coloca como antagonistas a "otros" (el Estado, los/as patrones/as, las empresas, etcétera), es que los estereotipos de género se constituyen en perpetradores/as de la injusticia hacia los propios compañeros, las compañeras y para cada mujer frente a sí misma, en la medida en que no puede reconocer ni ejercer sus propias capacidades.

\section{EL CAMBIO EN SINGULAR: EXPERIENCIAS DE MUJERES QUE BUSCAN ESPACIO}

A partir del análisis realizado, resulta posible identificar tres modos principales de valorar la vinculación con el Espacio. El siguiente testimonio permite presentar uno de ellos:

"Con Julio somos los referentes en la asamblea. Convocamos, organizamos y la hacemos en el barrio. A veces pasan días que Julio no viene, porque tiene cosas en el [emprendimiento] productivo, otras responsabilidades y bue... no viene, está bien... yo entiendo. Pero cuando viene... habla, dice esto, dice aquello y me da vuelta todo. Todo lo que venimos laburando y organizando... y no puede ser. Entonces le digo 'yo te respeto, te respeto como compañero... trabajemos a la par, organicemos juntos.... Y él me dice que yo hablo así porque voy al espacio de género [risas]. Mirá, no porque sea un hombre le voy a dejar de plantear las cosas. Y si no viene a las as ambleas, no voy a dejar de trabajar porque él no esté (...) Por eso yo veo que a míme sirve lo que aprendi en los talleres... me sirve... me sirve para mi vida cotidiana" (Irma, 46 años, Área de Productivos).

Irma representa cabalmente una de las vertientes principales de este espacio. Ella, como muchas otras, se acercó al MTD al que estaba vinculada en busca de recursos con los que afrontar la vida diaria en su hogar, en el que vive con sus cuatro hijos/as. En este proceso fue asumiendo cada vez mayores responsabilidades y participó en el Espacio de Mujeres desde los primeros encuentros.

Ella resalta cuánto le sirvió el encuentro con otras mujeres para "su vida cotidiana". Esto involucra fundamentalmente la relación con un compañero del movimiento, Julio, frente a quien aprendió a "hacerse respetar". Señala que Julio no siempre estaba presente en las asambleas del barrio, dado que muchas veces asumía el rol de vocero y estaba a cargo de otros espacios en el movimiento. Sin embargo, cuando se hacía 
presente, actuaba prescindiendo de lo resuelto en su ausencia y "le daba vuelta todo". El "aprendizaje" que ella resalta es el que le permite distinguir el respeto que le debe en tanto "compañero" -es decir, como un par- de la subordinación que no está dispuesta a aceptar en función de su condición de género. Vale decir, "no porque fuera un hombre" ella va a "dejar de plantear las cosas".

Irma describe su trayectoria en términos de un pasaje de "la necesidad a la política", de "ocuparme de lo mío a ocuparme de los demás". Esto último es valorado, por ella y otras mujeres, como una forma de acreditar capacidades que no sabían que tenían, tales como la de organizar una asamblea y -a partir de su participación en el Espaciohacerse respetar por un hombre, lo cual muestra que las huellas de esta experiencia no se limitan a visibilizar esas fuentes de menosprecio sino que la llevan a asumir nuevos valores y prácticas.

Por otro lado, una joven destaca otros aspectos de la experiencia realizada en el Espacio:

"Como organización nos integramos al Frente y empezamos a ir a los espacios de formación política, estuvimos en los encuentros de jóvenes, compartiendo experiencias con los compañeros del MST de Brasil, aprendimos mucho (...) Y ahora participando en el Espacio de Mujeres, viajando a los encuentros... es todo nuevo para mí. El año pasado fui por primera vez al Encuentro de Mujeres (...) Empezamos a darnos un laburo en la Universidad, por ejemplo el 8 de marzo, comentar, hacer acciones, pasar por los cursos a explicar que no es un día más, es un día de lucha (...) no es un día de flores o bombones [se ríe]" (Inés, 23 años, participa en el Área de Formación).

Inés representa otra vertiente, conformada por jóvenes militantes universitarios/ as autodefinidos como "clase media" y vinculados/as, en algunos casos, a grupos de izquierda. Se acercaron al FPDS buscando profundizar su conocimiento acerca de la vida y las expectativas de los sectores populares, lo que muchas de estas personas describían como "salir de la cajita de cristal" y, a la vez, incrementar la "conciencia" en estos sectores. Frente a estas expectativas de partida, Inés destaca el hecho de haberse encontrado con otros/as jóvenes con quienes "formarse políticamente", resaltando especialmente el encuentro con personas vinculadas al Movimiento Sin Tierra (MST) de Brasil, considerado un modelo en las prácticas a seguir en el FPDS.

Pero lo que aparece en su testimonio como un hallazgo es lo relativo a la militancia de género: el descubrimiento de otra forma de opresión, no de clase, que la involucraba desde otro lugar. En este sentido, su vinculación con el Espacio de Mujeres abrió nuevos horizontes en su militancia política. Así, la trayectoria de Inés puede describirse desde la búsqueda de acercar conciencia a los sectores populares a descubrir otras formas de opresión que desconocía y que padecía sin tener conciencia de ello. Mujeres como Inés descubren que sufren menosprecio (una falta de reconocimiento socialmente 
sancionada) cuando pueden anudar lo que pensaban como limitaciones personales a su condición de género.

Una tercera vertiente es la que está presente en el testimonio que revisamos a continuación:

"Nosotros estamos trabajando desde hace muchísimos años en la zona, es decir después de la dictadura, fundamentalmente, armamos un lugar que se llamaba Centro Cultural Berisso. El planteo general te lo podría definir como que era un poco la reconstrucción del tejido social. (...) Asífue como surgió esto y, bueno, cómo nos fuimos enganchando con el movimiento. Ese fue el origen, así fue la historia, así llegué yo a la organización, al MTD. Es decir, para mífue una continuidad, porque en la práctica yo soy militante de la década del '70. (...) En los '80... en ese momento histórico también vienen muchas mujeres del exterior, muchas compañeras nuestras que habian estado exiliadas, con ideas novedosas. Con ideas novedosas para mí, en ese momento, que era el tema de la mujer. (...) yo cuando empecé a entender el tema de mujeres... el paso siguiente de entender el feminismo fue facilísimo" (Ema, 52 años, responsable del Área de Formación).

Ema, como muchas otras mujeres, tiene una amplia trayectoria de militancia. Conoció la represión en los'70 y se reencontró con muchos/as compañeros/as de lucha en los '80, cuando el desafío era "reconstruir el tejido social".

Como casi todas las naciones sudamericanas, a lo largo del siglo XX Argentina atravesó prolongadas y sangrientas dictaduras militares. El terrorismo de Estado ejercido entre 1976 y 1983 convirtió en objeto de "aniquilamiento" a todas las expresiones de resistencia a las políticas neoliberales, a las que aglutinó bajo el rótulo de "subversivas"10. Al final de la dictadura, hubo una amplia coincidencia entre sectores académicos y militantes en cuanto a la necesidad de reconstruir el "tejido social" desgarrado por el horror, como prerrequisito para la reconstrucción de una democracia duradera (Jelin, 1985; Novaro y Palermo, 2003). Ema pertenecía a esa generación y, para ella, la militancia territorial, comenzada en un centro comunitario del conurbano, era una contribución en ese sentido.

A diferencia de Irma, para Ema la experiencia en los MTD no era la que le había permitido descubrir sus capacidades para constituirse en referente política. En este último caso, el feminismo no resultó una novedad. Lo que ella resalta de esta experiencia es la posibilidad de encauzar conjuntamente su trayectoria y su vocación política en el FPDS, y su militancia feminista en el Espacio.

10 La llamada "guerra contra la subversión", que comenzó a mediados de los años '70 y concluyó a fines de 1983, puso en escena un dispositivo de terrorismo de Estado que hizo objeto de su persecución a líderes, militantes, colaboradores/as y simpatizantes de organizaciones políticas, sindicales y religiosas, a partidarios/as o contrarios/as a la lucha armada, peronistas y antiperonistas, y también a sus amigos/as, familiares e hijos/as. 
De este modo, el camino recorrido por estas mujeres, desde la autoinculpación por no participar en asambleas hasta proponer la definición del cambio social en términos de una lucha "anticapitalista y antipatriarcal", no sólo tiene peso por sus implicancias públicas sino por su alcance en términos de los modos en que cada una vive la propia condición de "sujeto sexuado y generado" mujer (De Lauretis, 2000). Esto nos lleva a problematizar las diferencias entre las mismas mujeres y las que existen en cada subjetividad particular. Podemos decir que estas diferencias se expresan en los disímiles sentidos que circulan en torno a dos cuestiones: a) las temáticas trabajadas desde el Espacio de Mujeres y b) las propuestas consideradas para abordar problemáticas en conjunto. Veamos entonces de qué se trata cada una.

Por una parte, en las escenas de los "talleres vivenciales" y de "formación" se convoca diferentes expresiones sobre el ejercicio de la salud sexual y la procreación, la exposición del propio cuerpo, las identidades de género y las múltiples significaciones de la mujer en tanto "madre". En el trabajo en pequeños grupos, esta diversidad se expresó en lenguajes que manifestaron diferentes "prioridades". Dentro de las temáticas trabajadas, la problemática sobre la interrupción voluntaria del embarazo y el "derecho a decidir" sobre esta cuestión ha generado distintos debates entre las concurrentes. Desde los comienzos hasta las instancias más recientes, este tema se ha problematizado a través de "talleres" donde se ha invitado a profesionales de la salud para "trabajar con información" que recupere "los mitos en torno al aborto" (Partenio, Op. cit.).

En referencia a estas temáticas, consideramos que la expresión de las diferentes posiciones de las participantes -marcadas por su posición de clase, su generación y su etnia- nos lleva a considerar las formas en que se articula la experiencia, proceso en el cual la sexualidad juega un rol central "en cuanto determina, a través de la identificación genérica, la dimensión social de la subjetividad femenina" (De Lauretis, 1992: 290) y también "la experiencia personal de la condición femenina" (Ibíd: 291).

Por otra parte, estas diferencias también se han plasmado en las herramientas consideradas adecuadas para el abordaje de ciertos temas. Se han planteado divergencias en torno a "cómo" y "quiénes" pueden abordar las prácticas de "acompañamiento" y "contención" en casos de violencia de género. Estas ideas han desbordado los límites del propio Espacio, planteando la necesidad de la "intervención" como movimiento social. Sin duda, este es un tema aún no resuelto y plantea una tarea de trabajo futura que "las compañeras" coinciden en encarar.

Pensando en ambas cuestiones, nos interesa cerrar este apartado rescatando algunas texturas. Precisamente por esto, que alguna vez mencionó Audre Lorde (1982), el hecho de "estar juntas las mujeres no era suficiente" y fue necesario "un cierto tiempo" para habitar ese espacio marcado por las diferencias. En estas formas de habitar dicho espacio las experiencias permiten descubrir y articular el menosprecio sufrido, pero también ser capaces de ver el mundo desde el nuevo lugar que otorga haberse encontrado con otras y haber luchado junto a ellas. 


\section{REFLEXIONES FINALES}

A lo largo de estas páginas vimos cómo el Espacio de Mujeres se afianzó como un lugar de encuentro y discusión en el que confluyeron mujeres con trayectorias políticas, representaciones acerca de la participación de las mujeres y expectativas de transformación social diversas. Esta diversidad se expresó en la confrontación y/o convergencia de prácticas, herramientas, demandas y lenguajes distintos, y muchas veces complementarios.

En este proceso se puso de manifiesto que para cambiar la orientación patriarcal que se encuentra presente tanto en las interacciones sociales como en la división de tareas, "no se trata simplemente de modificar los comportamientos y los roles en la división sexual del trabajo, sino de minar, desgastar y desestabilizar sus cimientos y la ideología que de ellos emana" (Segato, 2003: 71). En este sentido, hablamos de prácticas que permiten avanzar en los debates políticos sobre el reconocimiento y la producción de demandas activas de derechos, intentando analizar la forma en que se fue articulando la experiencia de estas mujeres que fundaron -en tanto pioneras- o se sumaron a este espacio, sentido como propio.

El análisis realizado pone de relieve la necesidad de pensar articuladamente las experiencias subjetivas y la definición de las demandas de los movimientos sociales, proceso que resulta imposible si partimos de la unidad del movimiento social y de la equivalencia de quienes lo integran en términos de experiencias. Si todas estas mujeres se reconocían como "trabajadoras desocupadas", la riqueza que produjo su encuentro sólo se manifestó al momento de poner en juego aquello que las hace singulares. De hecho, para las propias mujeres del Espacio, este descubrimiento de aquello que las igualaba y de lo que las diferenciaba -que no siempre coincidía con sus ideas previas al respecto- fue lo que les permitió poner en tensión posiciones y relaciones de subalternidad que no siempre habían sido capaces de articular antes de su vinculación con este espacio. A lo largo del trabajo nos propusimos reconstruir esas experiencias, entendidas como el resultado de una compleja red de determinaciones y luchas (De Lauretis, 1992).

De este modo, en el camino recorrido en conjunto por estas mujeres se dieron profundos procesos de transformación de quienes involucraron su mente y su voz, pero también su cuerpo y su historia en el proceso. Como se ha podido ver, las huellas de las "luchas" a las que se vincularon son mucho más perdurables que los movimientos sociales en sí, pero constituyen -casi siempre-el punto de partida de nuevos procesos de movilización y expansión de los horizontes de libertad en una sociedad.

Sin embargo, el camino hacia la paridad participativa no está exento de tensiones. Entre ellas nos interesa resaltar dos fuentes de conflicto asociadas: la generización de las agendas y la tensión entre aspectos reivindicativos y políticos. La existencia de una agenda generizada puede aportar tanto al reconocimiento de la diversidad como a 
un "encapsulamiento" de las demandas de las mujeres, aislándolas del resto del movimiento. Asimismo, esta división puede conducir a posturas binarias que definan que, por oposición, aquello que no está en la agenda de las mujeres sea entonces cosa de varones.

Lo anterior se manifiesta en la desigualdad de poder fundamentada en la división generizada entre aspectos reivindicativos y políticos. Las mujeres suelen atender los aspectos reivindicativos (gestión de la política social, la atención de comedores y"roperos comunitarios", etc.), situación que termina dificultando su participación en ámbitos de representación y conducción política dentro de su movimiento. Teniendo presente esta división, las primeras mujeres que formaron el Espacio de Mujeres comenzaron por cuestionar las jerarquías, las cuales, en términos de Fraser (2006), no solamente estaban institucionalizadas en lugares de "referencia" política, sino en la misma división del trabajo de cada organización, de cada barrio.

A partir de esta situación se plantea un dilema político generado entre las reivindicaciones como mujeres y su conflictiva lealtad al grupo y a los hombres de éste (Segato, Op. cit.). De hecho, la creación de un espacio de mujeres fue experimentada con cierto recelo por los varones líderes, que lo visualizaban como una amenaza para la integridad del movimiento más que como una lucha movilizadora de recursos tanto para las reivindicaciones de derechos de las mujeres como para los derechos colectivos.

Como pudimos analizar, en los comienzos y como parte de las "necesidades" expresadas, el Espacio de Mujeres se construye para y desde las mujeres, a pesar de los cuestionamientos de algunos hombres. Ellas apuestan por una construcción y legitimación de este espacio como "una prioridad", como "una política del movimiento". De esta forma, el desafío consistía en instalar las concepciones provenientes del Espacio de Mujeres en instancias colectivas/mixtas del movimiento ("plenarias","mesas","asambleas"), en las cuales las líneas a seguir como organización son definidas.

En cuanto a las lecciones que nos deja este proceso, a partir de las posibilidades concretas de lucha social o articulación colectiva de experiencias de menosprecio para las mujeres pobres, sometidas a falta de reconocimiento y a una injusta distribución, hay dos que nos resultan centrales.

En primer lugar, resalta el hecho de que no toda falta de reconocimiento es idéntica. Suponer dos esferas diferenciadas, una para el reconocimiento y otra para la redistribución, significaría sostener la unidad en la condición de clase. Sin embargo, la experiencia de pobreza no se vive igual para hombres y mujeres, y las alternativas a mano para cuestionar la injusta distribución no son las mismas. Si para luchar por mejorar sus condiciones de vida una mujer debe someterse a la autoridad de un varón-dirigente, en función de una distribución estereotipada de roles que le niega la posibilidad de ir "más allá del barrio" o de lo "reivindicativo", entonces estará cambiando una experiencia de menosprecio por otra. Inclusive, la segunda puede resultar más 
dolorosa en tanto el enemigo de clase resulta lejano y difuso, pero el dirigente que la menosprecia es un compañero, un vecino, alguien con quien interactúa cotidianamente. Dada la distancia respecto al antagonista, las "luchas" no son las mismas. El enemigo de clase es externo, en cambio, el sostenimiento de la violencia patriarcal se juega en sentimientos, actitudes y pensamientos íntimamente arraigados en nosotras mismas tanto como en los hombres con quienes interactuamos cotidianamente.

La segunda lección tiene que ver con la discusión sobre lo potente del concepto de experiencia para dar cuenta de procesos como el aquí considerado. A pesar de la heterogeneidad de sus trayectorias y expectativas, podemos decir que junto con todas estas mujeres hemos recorrido un extenso e intenso camino en el que no han sido los debates sofisticados ni los argumentos razonados lo que nos abrió a la posibilidad de nuevas perspectivas. Al contrario, fueron las lágrimas enjugadas y vertidas, los abrazos y los desencuentros, la emoción al marchar lo que nos permitió entender el mundo de las otras y, a la vez, situarnos de otro modo en el mundo. Así, el proceso que se cuenta en este texto de un modo encadenado está hecho de encuentros y desencuentros, cuyo fin no hubiera sido posible anticipar por ninguna de nosotras, aunque luego hayamos tenido la sensación de que era más de lo que hubiéramos podido desear.

\section{BIBLIOGRAFÍA}

Bach, Ana María (2008): "La revalorización de la categoría de experiencia por parte de las teorías feministas norteamericanas: 1980-2000", Tesis (Doctorado en Filosofía). Buenos Aires: UBA, Facultad de Ciencias Sociales.

Brincker, Benedikte y Gundelach, Peter (2005): "Sociologists in action: a critical exploration of the intervention method", en Acta Sociológica, Vol. 48, No. 4, pp. 365-375.

Calvo, Dolores (2003): "Organización política auto-referenciada en sectores populares. El caso de la Federación de Tierra, Vivienda y Hábitat" [on line]. Disponible en: http:// bibliotecavirtual.clacso.org.ar/ar/libros/becas/levy/07calvo.pdf [Recuperado el 24 de noviembre de 2009]

Cross, Cecilia (2010): "'Ves otras personas en nosotros mismos': experiencias de vinculación en organizaciones territoriales de Buenos Aires", en Cuadernos de Antropología Social, No. 31, pp. 55-74.

De Lauretis, Teresa (1992): Alicia ya no. Feminismo, semiótica y cine. Madrid: Cátedra. (2000): Diferencias. Etapas de un camino a través del feminismo. Madrid: horas y HORAS.

Espacio de Mujeres del Frente Popular Darío Santillán (2007): Primer Campamento de Formación en Géneros. Cartilla de formación. Buenos Aires: FPDS. 
Fraser, Nancy (1997): Iustitia interrupta: reflexiones críticas desde la posición "postsocialista". Bogotá: Siglo del Hombre Editores.

(2000): "Rethinking recognition", en New Left Review, Vol. 3, pp. 107-120.

- (2006): "La justicia social en la era de la política de la identidad: redistribución, reconocimiento y participación", en Fraser y Honneth: ¿Redistribución o reconocimiento?, pp. 17-85. Barcelona: Morata / Paideia.

Frente Popular Darío Santillán (2004):"Nuestra política para construir un presente y un futuro con trabajo, dignidad y cambio social", Versión 1.0. [on line]. Buenos Aires. Disponible en: http://www4.autistici.org/mtdenelfrente/politica/ind politica. htm\#arriba\#arriba [Recuperado el 1 de noviembre de 2009]

(2007): “Qué es el Frente Popular Darío Santillán?" [On line]. Buenos Aires. Disponible en: http://www.frentedariosantillan.org/1/index.php?blog=15\&cat=175 [Recuperado el 1 de noviembre de 2009]

Giarraca, Norma (2001): "El Movimiento de Mujeres Agropecuarias en Lucha: protesta agraria y género durante el último lustro en Argentina", en Giarraca (comp.): ¿Una nueva ruralidad en América Latina?, pp. 129-151. Buenos Aires: CLACSO / ASDI.

Gorlier, Juan Carlos (2004): Comunidades narrativas. El impacto de la praxis feminista sobre la teoría social. La Plata: Ediciones Al Margen.

Haraway, Donna (1995): Ciencia, cyborgs y mujeres. La reinvención de la naturaleza. Madrid: Cátedra.

Honneth, Axel (1997): La lucha por el reconocimiento: Por una gramática moral de los conflictos sociales. Barcelona: Crítica/Grijalbo Mondadori.

- (2006): "Redistribución como reconocimiento: respuesta a Nancy Fraser", en Fraser y Honneth: ¿Redistribución o reconocimiento?, pp. 93-125. Barcelona: Morata/ Paideia.

(2007): Reificación: un estudio en la teoría del reconocimiento. Buenos Aires: Katz Editores.

Jelin, Elizabeth (1985): "Otros silencios, otras voces. El tiempo de la democratización en la Argentina", en Calderón, Fernando (comp.): Los movimientos sociales ante la crisis, pp. 17-44. México: UNU / CLACSO / IISUNAM.

Lorde, Audre (1982): Zami: A New Spelling of My Name. Berkeley: The Crossing Press. 
Mazzeo, Miguel (2004): Piqueteros. Notas para una tipología. Buenos Aires: FISyP / Manuel Suárez Editor.

Melucci, Alberto (1999): Acción colectiva, vida cotidiana y democracia. México: Colegio de México.

Merklen, Denis (1991): Asentamientos de La Matanza: La terquedad de lo nuestro. Buenos Aires: Catálogos.

(2005): Pobres ciudadanos: las clases populares en la era democrática (Argentina 1983-2003). Buenos Aires: Gorla.

Molina Petit, Cristina (2007): "El feminismo socialista estadounidense desde la 'Nueva Izquierda'. Las teorías del sistema dual (capitalismo+patriarcado)", en Amorós y de Miguel (eds.): Teoría feminista: de la ilustración a la globalización. Del feminismo liberal a la posmodernidad. 2, pp. 147-185. Madrid: Minerva Ediciones.

Novaro, Marcos y Palermo, Vicente (2003): "La dictadura militar 1976-1983": del golpe de Estado a la restauración democrática, en Halperin, Tulio (dir.): Historia Argentina, Tomo 9. Buenos Aires: Paidós.

Offe, Clauss (1985): La sociedad del trabajo. Problemas estructurales y perspectivas futuras. Madrid: Alianza.

Partenio, Florencia (2009): "Género y participación política: los desafíos de la organización de las mujeres dentro de los movimientos piqueteros en Argentina", en Informe final: Las deudas abiertas de América Latina y el Caribe, pp. 1-36. Buenos Aires: CLACSO / ASDI.

Schuster, Federico y Pereyra, Sebastián (2001): "La protesta social en la Argentina democrática", en Giarraca, Norma et al.: La protesta social en la Argentina. Transformaciones económicas y crisis social en el interior del país, pp. 41-63. Buenos Aires: Alianza.

Segato, Rita (2003): Las estructuras elementales de la violencia. Ensayos sobre género entre la antropología, el psicoanálisis y los Derechos Humanos. Buenos Aires: Universidad Nacional de Quilmes / Prometeo.

Svampa, Maristella y Pereyra, Sebastián (2003): Entre la ruta y el barrio: La experiencia de las organizaciones piqueteras. Buenos Aires: Biblos.

Tejerina, Benjamín (1998): "Los movimientos sociales y la acción colectiva. De la producción simbólica al cambio de valores", en Ibarra y Tejerina (eds.): Los movimientos sociales, pp. 127-138. Madrid:Trotta. 
Tarrow, Sydney (1994): El poder en movimiento: Ios movimientos sociales, la acción colectiva y la política. Madrid: Alianza Universidad.

Throop, C. Jason (2003): "Articulating experience", en Anthopological Theory, Vol. 3, No. 2, pp. 219-241.

Zald, John y Mc Carthy, Mayer (1987): Social movements in organizational society. New Brunswick: Transaction. 